\title{
Is the water in dental units clean?
}

\author{
A cross sectional study of water quality from dental unit water lines in dental practices in the West of Scotland \\ A. J. Smith, S. McHugh, L. McCormick, R. Stansfield, A. McMillan and J. Hood Br Dent J 2002; 193: 645-648
}

\section{Objective}

To determine the microbiological quality of water from dental units in a general practice setting and current practice for disinfection of units.

\section{Design}

A cross-sectional study of the water quality from 40 dental units in 39 general practices and a questionnaire of the disinfection protocols used in those practices.

\section{Setting}

NHS practices in primary dental care.

Subjects

Thirty-nine general practices from the West of Scotland.

\section{Methods}

Water samples were collected on two separate occasions from dental units and analysed for microbiological quality by the total viable count (TVC) method. Water specimens were collected from the triple syringe, high speed outlet, cup filler and surgery tap. Each participating practitioner was asked to complete a questionnaire.

\section{Results}

Microbial contamination was highest from the high speed outlet followed by the triple syringe and cup filler. On average, the TVC counts from the high speed water lines at $37^{\circ} \mathrm{C}$ and for the high speed lines, triple syringe and cup filler at $22^{\circ} \mathrm{C}$ were significantly higher than that from the control tap water specimens. The study included units from 11 different manufacturers with ages ranging from under one year to over eight years. The age of the dental unit analysed did not appear to influence the level of microbial contamination. Five of the practices surveyed used disinfectants to clean the dental units but these had no significant effect on the microbiological quality of the water. The majority of dental units (25 out of 40) were never flushed with water between patients. A number of different non-sterile irrigants were used for surgical procedures.

\section{Conclusion}

The microbiological quality of water from dental units in general dental practice is poor compared to that from drinking water sources. Suitable sterile irrigants should be used for surgical procedures in dental practice. Further work is required for pragmatic decontamination regimens of dental unit water lines in a general dental practice setting

\section{COMMENT}

This paper describes a study of water lines from dental units in the west of Scotland. Considerable numbers of bacteria were found in the water lines, which were more than would be found or acceptable in drinking water. The numbers of bacteria found was not influenced by the age of the unit as even relatively new units (circa one year) were found to be heavily contaminated. The contamination of the dental unit water supplies was not eradicated by the use of disinfectants. The highest counts of bacteria were found in the high-speed turbine outlets presumably where backsiphonage was a significant problem.

Most dental practitioners who have followed the literature on contamination of dental unit water supplies will wonder why this contamination problem has not been solved. Surely, as the authors suggest, some pragmatic solution to the contamination of dental unit water supplies must be found. The problem is highly complex to solve as the bacteria that are released into the planktonic phase of the dental unit water supplies are generated from biofilms in the walls of tubing. Biofilms are tenacious layers strongly adherent to the walls of the tubing and often containing many different bacteria. Once in a biofilm, bacteria which may be sensitive to disinfectants when grown on their own, become resistant. The biofilm also often contains carbohydrate- containing material, which physically protects them from disinfectant action. It is therefore not surprising, as reported in this paper, that disinfectants did not eradicate the problem. Safe methods of removal of biofilm from dental units have not yet been found despite intensive research.

Does the presence of bacteria in dental unit water supplies have any clinical significance? The presence of such a high inoculum of bacteria in dental units certainly precludes the use of this water as an irrigant during invasive minor oral surgery: sterile water must be used. Contaminated dental unit supplies should also not be used on medically compromised patients as it could cause infection. ${ }^{1}$ It is likely that in healthy patients the bacterial contamination may not be significant, but it does from time to time arouse media interest. The dental profession does need a solution to the apparently intractable question

Michael V. Martin, Senior Lecturer and Honorary Consultant Microbiologist

Department of Clinical Dental Sciences, University of Liverpool,

1. Martin M V. The significance of the bacterial contamination of dental unit water supplies. BrDent J 1987: 163: 152-154

\section{IN BRIEF}

- Work describes widespread microbial contamination of dental unit water lines which appears unrelated to age and make of unit.

- Recommendations use of sterile irrigants for surgical procedures.

- Suggests that units should be redesigned to reduce build up of biofilm. 